\title{
Using distance sampling with camera traps to estimate the density of group-living and solitary mountain ungulates
}

\author{
Ranjana Pal, Tapajit Bhat Tacharya, Qamar QuReshi

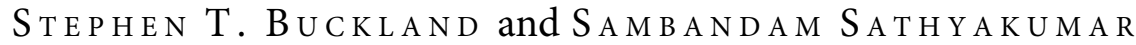

\begin{abstract}
Throughout the Himalaya, mountain ungulates are threatened by hunting for meat and body parts, habitat loss, and competition with livestock. Accurate population estimates are important for conservation management but most of the available methods to estimate ungulate densities are difficult to implement in mountainous terrain. Here, we tested the efficacy of the recent extension of the point transect method, using camera traps for estimating density of two mountain ungulates: the group-living Himalayan blue sheep or bharal Pseudois nayaur and the solitary Himalayan musk deer Moschus leucogaster. We deployed camera traps in 2017-2018 for the bharal (summer: 21 locations; winter: 25$)$ in the trans-Himalayan region $(3,000-$ 5,000 $\mathrm{m}$ ) and in 2018-2019 for the musk deer (summer: 30 locations; winter: 28$)$ in subalpine habitats $(2,500-$ $3,500 \mathrm{~m}$ ) in the Upper Bhagirathi basin, Uttarakhand, India. Using distance sampling with camera traps, we estimated the bharal population to be $0.51 \pm \mathrm{SE} 0.1$ individuals/ $\mathrm{km}^{2}(\mathrm{CV}=0.31)$ in summer and $0.64 \pm \mathrm{SE} 0.2$ individuals/ $\mathrm{km}^{2}(\mathrm{CV}=0.37)$ in winter. For musk deer, the estimated density was $0.4 \pm \mathrm{SE} 0.1$ individuals $/ \mathrm{km}^{2}(\mathrm{CV}=0.34)$ in summer and $0.1 \pm \mathrm{SE} 0.05$ individuals $/ \mathrm{km}^{2}(\mathrm{CV}=0.48)$ in winter. The high variability in these estimates is probably a result of the topography of the landscape and the biology of the species. We discuss the potential application of distance sampling with camera traps to estimate the density of mountain ungulates in remote and rugged terrain, and the limitations of this method.
\end{abstract}

Keywords Bharal, camera trapping, density estimates, musk deer, point transect method, subalpine, transHimalaya, Upper Bhagirathi basin

Supplementary material for this article is available at doi.org/10.1017/So03060532000071X

SAMBANDAM SATHYAKUMAR (Corresponding author, (1) orcid.org/0000-0003-

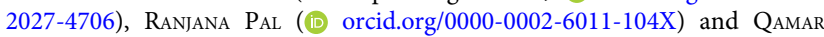
QURESHI Wildlife Institute of India, Chandrabani, Dehradun, Uttarakhand 248001, India. E-mail ssk@wii.gov.in

TAPAIT BHATtaCharya (iㅣ orcid.org/0000-0002-1154-4033) Durgapur Government College, Durgapur, India

STePHen T. Buckland (10) orcid.org/0000-0002-9939-709X) The Centre for Research into Ecological and Environmental Modelling, University of St Andrews, St Andrews, UK

Received 20 January 2020. Revision requested 29 May 2020

Accepted 22 July 2020. First published online 30 April 2021.

\section{Introduction}

Tngulates are an integral component of Himalayan mammalian fauna and play an essential role in shaping ecosystems by influencing vegetation structure (McNaughton, 1979; Bagchi \& Ritchie, 2010) and as primary prey for large predators (Bagchi \& Mishra, 2006; Sathyakumar et al., 2013a). Population estimates are important for effective conservation management (Singh \& Milner-Gulland, 2011; Suryawanshi et al., 2012). Methods to estimate animal abundance include distance sampling (Buckland et al., 2001), track count (Sulkava \& Liukko, 2007), dung count (Laing et al., 2003), the abundance induced heterogeneity model (Royle \& Nichols, 2003), repeated count (Royle, 2004) and the double observer method (Forsyth \& Hickling, 1997; Suryawanshi et al., 2012; Suryawanshi et al., 2020). In mountains, however, rugged and steep terrain, inaccessibility and harsh weather conditions make these techniques less effective (Singh \& Milner-Gulland, 2011).

As a consequence, several studies on mountain ungulates have used an indirect index of abundance (e.g. Schaller et al., 1988; Sathyakumar, 1994; Bagchi \& Mishra, 2006; McCarthy et al., 2008; Suryawanshi et al., 2010) as an alternative to absolute abundance. However, these estimates are less reliable and highly dependent on the assumption of constant detection probability throughout the survey period (Yoccoz et al., 2001). In addition, small population sizes, cryptic and elusive behaviour, and patchy distribution of Himalayan ungulates limit the number of observations that can be made for a given survey effort (Singh \& Milner-Gulland, 2011). Forest-dwelling mountain ungulates may have activity peaks at night (Cavallini, 1992; Bhattacharya et al., 2012a) and are rarely detected during day-time surveys.

Distance sampling is one of the most popular methods for assessing the density of large herbivores in tropical forests (Buckland et al., 2001). However, meeting the underlying assumptions of this method in the mountains is difficult (Corlatti et al., 2015), which can lead to underestimation of population sizes. In the mountains, non-random locations of non-linear transects, inaccurate measurements of sighting distance and angle, and elusive behaviour of target species violate the assumptions underlying conventional distance sampling (O’Neill, 2008; Singh \& Milner-Gulland, 2011). Furthermore, the structure of mountainous terrain can hamper animal detectability, as animals hidden behind 


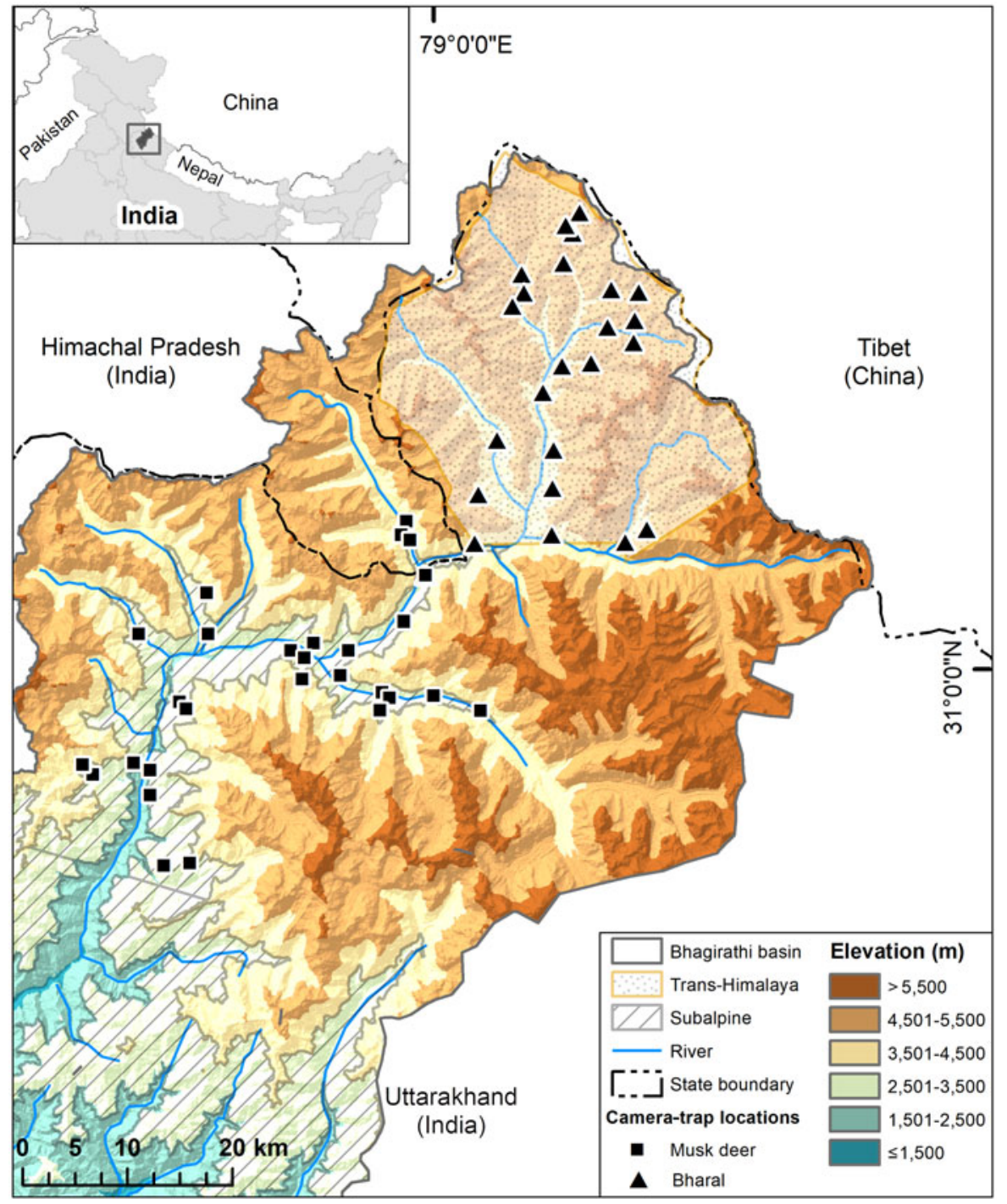

FIG. 1 Study area in the trans-Himalayan region and subalpine region of the Upper Bhagirathi basin, with the locations of camera traps used for estimating densities of the bharal Pseudois nayaur, and Himalayan musk deer Moschus leucogaster, respectively. The inset map shows the location of the Bhagirathi basin in Uttarakhand State, Western Himalaya, India. rocks or in valleys could remain undetected, irrespective of their distance from the observer.

Camera traps are an efficient tool for detecting elusive and rare species in remote habitats (Burton et al., 2015; Rovero \& Zimmermann, 2016), and extending the point transect method to accommodate data from camera traps could help solve some of the issues related to the violation of the assumptions underlying classic distance sampling (Howe et al., 2017). Distance sampling with camera traps has recently been tested for estimating the populations of Maxwell's duiker Philantomba maxwellii (Howe et al., 2017) and the western chimpanzee Pan troglodytes versus (Cappelle et al., 2019) in Côte d'Ivoire. However, the efficacy of this technique in mountainous terrain has yet to be tested.

Mountain ungulates are threatened by hunting for meat and body parts (Sathyakumar et al., 2013a,b), habitat loss (Namgail et al., 2007; Kittur et al., 2010) and competition with livestock (Mishra et al., 2004; Bhattacharya et al., 2012b) throughout the Himalaya. Here, we focused on the Himalayan blue sheep or bharal Pseudois nayaur and the Himalayan musk deer Moschus leucogaster, both of which are affected by anthropogenic impacts (Mishra et al., 2004; Bhattacharya \& Sathyakumar, 2011). The bharal is a social species of the Caprinae subfamily. It is associated with alpine and steppe mountain pastures, and subalpine slopes devoid of tree cover (2,500-5,500 m; Prater, 1980; Sathyakumar \& Bhatnagar, 2002). The species is categorized as Least Concern on the IUCN Red List and listed in Schedule I of the Indian Wildlife (Protection) Act, 1972. In contrast, the Himalayan musk deer is solitary and sedentary, remaining within a defined home range throughout the year. The musk deer, a primitive deer-like ruminant, is a member of the family Moschidae. In the Indian Himalayan region, the southern side of the Greater Himalaya, it is restricted to areas between 2,500 $\mathrm{m}$ and the treeline (Green, 1985; Sathyakumar et al., 2013b). It is categorized as Endangered on the IUCN Red List (Timmins \& Duckworth, 2015) and listed in the Indian Wildlife (Protection) Act, 1972, in Schedule I. 


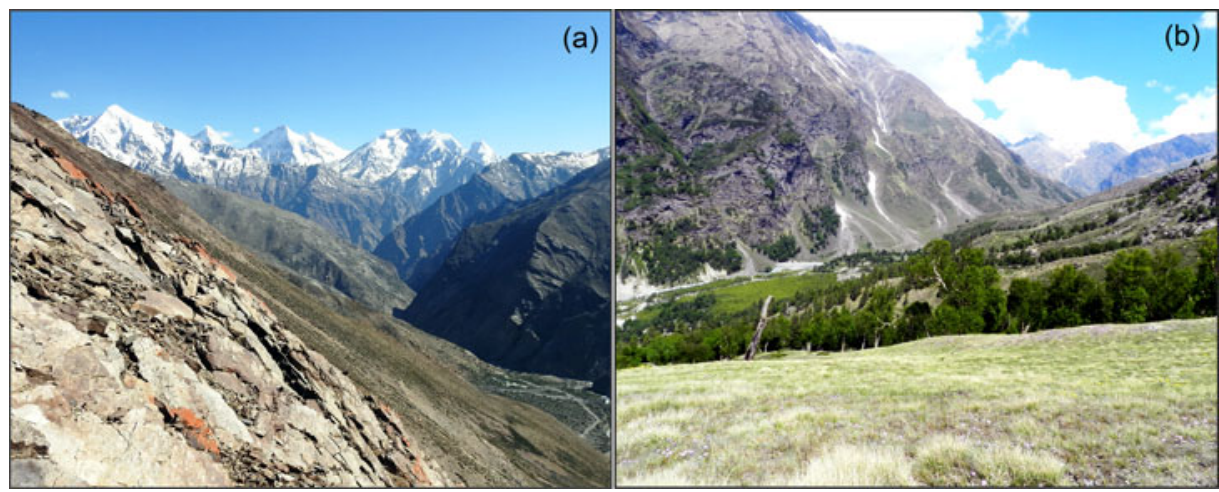

Plate 1 The study was conducted in the trans-Himalayan part (Nilang valley) of Gangotri National Park characterized by dry alpine scrub vegetation, broken terrain, deep gorges, high gradient slopes, and narrow valleys (a), and in the subalpine portion of the Park and Uttarkashi Forest Division (b) within Uttarakhand State, India.

Here, we tested the efficacy of the extension of the distance sampling method to accommodate camera-trap data for estimating the density of the group-living bharal in the trans-Himalayan region $(3,500-5,500 \mathrm{~m})$ and the solitary Himalayan musk deer in the subalpine region $(2,500-3,500 \mathrm{~m})$ of the Upper Bhagirathi basin. We examined the field applicability and possible limitations of this method for estimating the density of these two ungulates in mountainous terrain.

\section{Study area}

We carried out this study in the trans-Himalayan part (Nilang valley) of Gangotri National Park, in the subalpine portion of the Park and Uttarkashi Forest Division within Uttarakhand State, India (Fig 1, Plate 1). Nilang valley is characterized by broken terrain, deep gorges, steep slopes $\left(>45^{\circ}\right)$ and narrow valleys (Bhardwaj et al., 2010). The study area does not have permanent human settlements, but the alpine and subalpine zones are seasonal grazing ground for livestock from lower parts of the Bhagirathi basin. Tourists also use the area in summer (June-September). Nilang valley forms the international boundary with Tibet and is controlled by military personnel. There is a network of snow-fed tributaries of the Jadh Ganga, which drains the area to meet the Bhagirathi River. We surveyed areas of dry alpine scrub vegetation at 3,000-5,200 $\mathrm{m}$ for the bharal, and subalpine habitats dominated by Betula utilis, Pinus wallichiana, Quercus semecarpifolia and Cedrus deodara, at 2,5003,000 $\mathrm{m}$, for the Himalayan musk deer.

\section{Methods}

\section{Data collection}

We divided the study area into grid cells of $3 \times 3 \mathrm{~km}$. In each grid cell, we generated 20 random points using a sampling tool in ArcGIS 10.4 (Esri, Redlands, USA), and selected accessible points for the placement of camera traps. Some randomly generated locations were inaccessible because of precipitous terrain or the presence of seasonal pastoral nomad camps. We deployed camera traps (Cuddeback blue series, Cuddeback, De Pere, USA) to capture the bharal at 21 locations during summer (May-September 2017; 2,205 trap nights) and 25 locations during winter (October 2017January 2018; 1,786 trap nights) in the trans-Himalayan region of Gangotri National Park (Fig. 1). For the Himalayan musk deer, we set up camera traps in subalpine habitat, at 30 locations during summer (May-September 2018; 2,246 trap nights) and 28 locations during winter (October 2018January 2019; 964 trap nights). Camera traps were mounted $30-35 \mathrm{~cm}$ above the ground, and programmed to trigger immediately and record an image followed by a 30-s video when movement was detected.

Distance analysis requires calculating distance of the target species from the observer, in our case from the camera. To estimate the distance of photo-captured individuals from the camera trap, we calibrated image measurements against actual measurements during camera installation. For this, we took measurements using a calibration pole of known height at known distances from the camera, in the centre and along both sides of the camera's field of view. This calibration was done for a total of 30 camera traps, and we considered the measurements taken at these locations representative for others with similar topography and field of view.

\section{Data analysis}

Test for sampling bias To test whether we had sampled all elevations and topographic features according to their availability in the landscape, we compared elevation, ruggedness, slope and aspect of camera-trap locations and 100 randomly generated points using a non-parametric Mann-Whitney $\mathrm{U}$ test for scale variables (elevation, slope, ruggedness) and Bonferroni confidence intervals for the categorical variable (aspect). We resampled elevation data from the Shuttle Radar Topography Mission, at $1 \mathrm{~km}$ resolution (Jarvis et al., 2008). We calculated slope, ruggedness and aspect information using spatial analyst from the Digital Elevation Model in ArcGIS.

Availability for detection With camera traps, we can only estimate the density of populations that are available for 


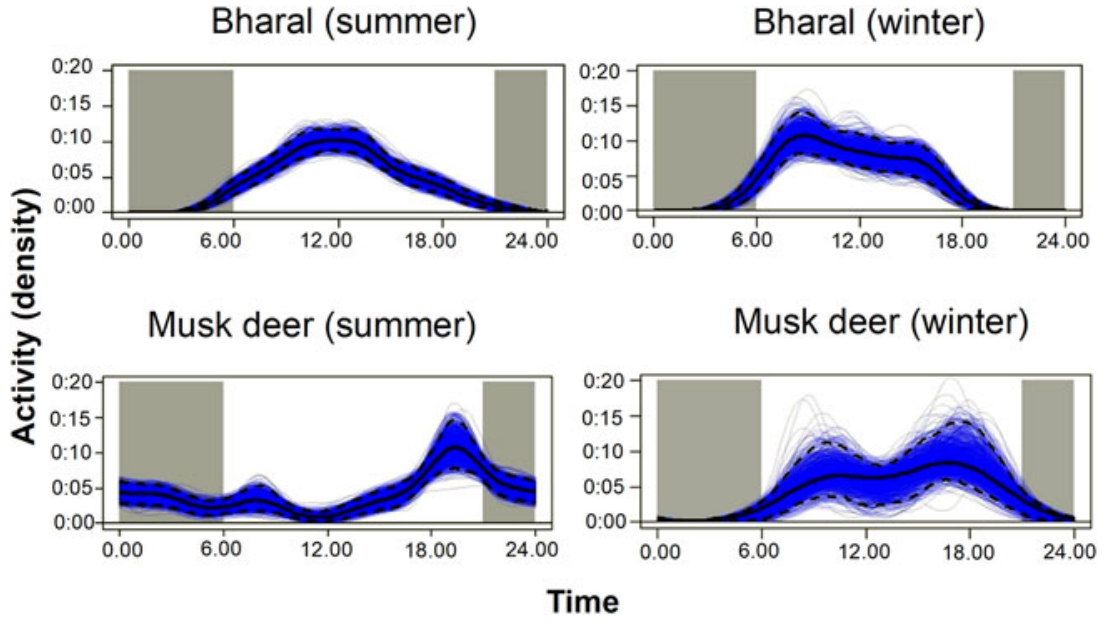

FIG. 2 Kernel density estimates of daily activity pattern of the bharal and the musk deer in summer and winter in the Upper Bhagirathi basin. detection (Howe et al., 2017). If the population surveyed is not available for detection during the data collection period selected for analysis, temporal sampling effort is overestimated, and as a result, density could be underestimated (Cappelle et al., 2019). To avoid this bias, either the sampling period should be defined as the time during which the entire population was available for detection (peak activity period) or the proportion of time when animals were available for detection should be included as a parameter in the model (Howe et al., 2017). In our study, the bharal was active during 6.00-18.00, without a marked peak in activity (Fig. 2). The Himalayan musk deer was active at night (18.00-6.00) in summer and during the day (6.00-20.00) in winter (Fig. 2). We used the active period of each species as the sampling period for the analysis. We corrected for the bias caused by animals being unavailable for detection by calculating the mean proportion of animals that were active during the period selected for analysis and incorporating this proportion in the density estimates. For example, for the bharal we first plotted the number of independent captures (i.e. at least a 30-minute interval between subsequent captures) to visualize the activity pattern of the species (Fig. 2). We assumed that if all animals were active throughout the day, then the curve would be a flat line between 6.00 and 18.0o. On the other hand, if all the animals were active around 12.00 (at the highest point of the curve), then this flat line will coincide with the curve at 12.00. We calculated both the areas under the imaginary flat line and under the actual activity curve shown in Fig. 2. We then calculated the mean proportion of animals that are active between 6.00 and 18.00 by dividing the proportion of the area under the actual activity curve by the area under the imaginary flat line, where animal activity reaches a peak. The estimated mean proportion of animals that are active during the period selected for analysis was 0.75 in summer and 0.8 in winter for the bharal. For the Himalayan musk deer it was 0.65 in summer and 0.7 in winter. We used the proportion of time animals are active to correct the naïve density estimate by dividing it by proportion of time active, using Distance 7.o (Thomas et al., 2010).

Density estimation Distance sampling with camera traps requires calculating the distance between the animal and the camera at snapshot moments to ensure that animal movement does not bias the distribution of detection distances (Howe et al., 2017). We thus defined a finite set of snapshot moments (2 s apart) within the sampling period (as suggested in Howe et al., 2017). For each snapshot moment when the species was captured, we estimated the radial distance between each animal and the camera trap, using a regression equation developed from the field calibration. In this equation, the dependent variable was the ratio of the actual height of an individual to its height in the photograph, and the explanatory variable was the distance at which the individual was photocaptured (see Supplementary Material 1 for details). We obtained information on actual heights for different age and sex classes of the bharal by comparing the camera-trap photos of the species with the height of the calibration pole height. We identified eight, 14, two and 10 comparable photographs of adult males, adult females, subadults and fawns, respectively. We calculated the mean height as $76.3 \pm$ SE $2.4 \mathrm{~cm}$ (adult male), 70.0 \pm SE $1.1 \mathrm{~cm}$ (adult female) and 64.0 \pm SE $1.0 \mathrm{~cm}$ (subadult) and 47.3 \pm SE $1.9 \mathrm{~cm}$ (fawn). For adult Himalayan musk deer we used a mean height of $50 \mathrm{~cm}$ (Sathyakumar et al., 2013b) to estimate their distance from the camera.

Density was estimated following the equation for camera-trap point transects (Howe et al., 2017):

$$
\hat{D}=\frac{\sum_{k=1}^{K} n_{k}}{\pi w^{2} \sum_{k=1}^{K} e_{k} \hat{P}_{k}} \times \frac{1}{A}
$$

where $n_{k}$ is the number of observations of animals at a point $k$ (camera-trap location), $e_{k}$ is the temporal effort, and $\hat{P}_{k}$ is 
the estimated probability of obtaining an image of an animal that is within $\theta$ degrees (angle covered by the camera's field of view), $K$ is the total number of camera-trap locations and $w$ (truncation distance) in front of the camera at a snapshot of the moment. The effort at a point $k$ was measured as $e_{k}=\theta T_{k} / 2 \pi t$ where $\theta / 2 \pi$ describes the fraction of a circle covered by a camera, $T_{k}$ is the period of camera deployment (in seconds), and $t$ is the unit of time used to determine a finite set of snapshot moments within $T_{k}$ (also in seconds). We defined the period of camera deployment as the time the target species was expected to be active during the sampling period. For the bharal, this was a 12-hour period per day (6.00-18.00) in both seasons and for the Himalyan musk deer a 12-hour period per day (18.00-6.00) in summer and a 14-hour period per day (6.00-20.00) in winter. $1 / A$ is the availability correction factor.

Seven camera traps malfunctioned because of technical errors and were not included in the final analysis. For the analysis in Distance, we modelled the detection from using the same functions as Howe et al. (2017): half normal with o, 1 or 2 Hermite polynomial adjustment terms; hazard rate with 0,1 , or 2 cosine adjustments; uniform with 1 or 2 cosine adjustments. As model selection methods based on Akaike's information criterion (AIC) tend to favour overly complex models because of overdispersion in the data, we selected models using a recently proposed two-step procedure (Howe et al., 2019): (1) Firstly, the best model is selected on the basis of AIC adjusted for overdispersion (QAIC) within each key function, where the overdispersion parameter $(\hat{\mathrm{C}})$ is calculated from the ratio between the $\chi^{2}$ statistics of the most parameterized model for each key function and its degrees of freedom $\left(\chi^{2} / d f\right)$. (2) Secondly, the best model is selected with the smallest values of the $\chi^{2}$ goodness-of-fit statistic divided by its degrees of freedom (across QAICselected models, one from each key function). We used the point transect distance sampling method in Distance (Thomas et al., 2010) for all analyses.

\section{Results}

\section{Sampling bias test}

In case of the Himalayan musk deer, the elevation, ruggedness and slope of sampled camera-trap locations were not biased: the mean values of sampled locations were not significantly different from the mean elevation, ruggedness and slope of 100 random points in both seasons $(P>0.05$ in each case, Mann-Whitney $U$ test; Supplementary Fig. 1). Bonferroni confidence intervals indicated no particular aspect category was preferred for sampling in winter or summer (Supplementary Fig. 1). Similarly, in the case of the bharal, the ruggedness, elevation and slope of the sampled camera locations were not different from the mean ruggedness, elevation, slope and aspect of the random points (Supplementary Fig. 2). Encounter rates were highly variable amongst locations and did not show any spatial autocorrelation for the bharal (Moran's I P: 0.6 in summer, 0.9 in winter) or the musk deer (Moran's I $P$ : 0.8 in summer, 0.6 in winter).

\section{Density estimates}

The bharal was photo-captured by 17 out of 21 camera traps deployed in summer, and 14 out of 24 in winter. We obtained 1,059 snapshots in 104 videos in summer and 949 snapshots in 61 videos in winter. In summer, one of the cameras contributed a large number of captures (c. $60 \%$ of the total dataset). This particular camera was placed on a steep slope with cliffs on both sides, and close $(10-15 \mathrm{~m})$ to an intensively used bharal trail along a stream. Consequently, a large number of observations by this camera were within 9-12 $\mathrm{m}$ as most of the bharals followed the path to move up or down the slope. Because of this bias, the initially estimated density of $0.15 \pm$ SE 0.31 individuals $/ \mathrm{km}^{2}$ had a high CV (207.35). We removed this camera from the final analysis to get an estimate with reduced bias. Amongst the summer captures, we found an excess of distances close to the camera (Fig. 3). The hazard-rate model is more sensitive than the halfnormal model to this excess, resulting in an implausible rapid fall-off in the detection probability. Therefore, we used the second-best model (Table 1), the half-normal model, for estimating bharal density in summer (0.51 \pm SE 0.1 individuals $\left./ \mathrm{km}^{2}, \mathrm{CV}=0.31\right)$. In winter, the best model was the hazard-rate model, and the second-best halfnormal model resulted in the same density estimates (o.64 \pm SE 0.2 individuals $/ \mathrm{km}^{2}, \mathrm{CV}=0.37$; Table 1).

Himalayan musk deer were captured by 11 out of 28 cameras in summer and 6 out of 25 cameras in winter. We obtained 564 snapshots in 102 videos in summer and 166 snapshots in 31 videos in winter. Himalayan musk deer data did not show the heterogeneity in capture probabilities amongst cameras that we observed for the bharal, nor any evidence of bias in terms of distances (Fig. 3). The best model was the hazard-rate model with cosine adjustment in both seasons (Table 1), and estimated density was $0.4 \pm \mathrm{SE} 0.1$ individuals $/ \mathrm{km}^{2}(\mathrm{CV}=0.34)$ in summer and 0.1 $\pm \mathrm{SE} 0.05$ individuals $/ \mathrm{km}^{2}(\mathrm{CV}=0.48)$ in winter (Table 1$)$.

\section{Discussion}

Our estimates of bharal density in summer (0.5 \pm SE 0.1 individuals $\left./ \mathrm{km}^{2}\right)$ and winter $\left(0.6 \pm \mathrm{SE} 0.2\right.$ individuals $\left./ \mathrm{km}^{2}\right)$ were similar. Estimates of bharal densities from three different locations in Spiti, the nearest trans-Himalayan landscape (using standardized double observer method; Suryawanshi et al., 2012) were 1.60, 1.49 and $3.19 / \mathrm{km}^{2}$. Estimates of bharal 
Bharal (summer)
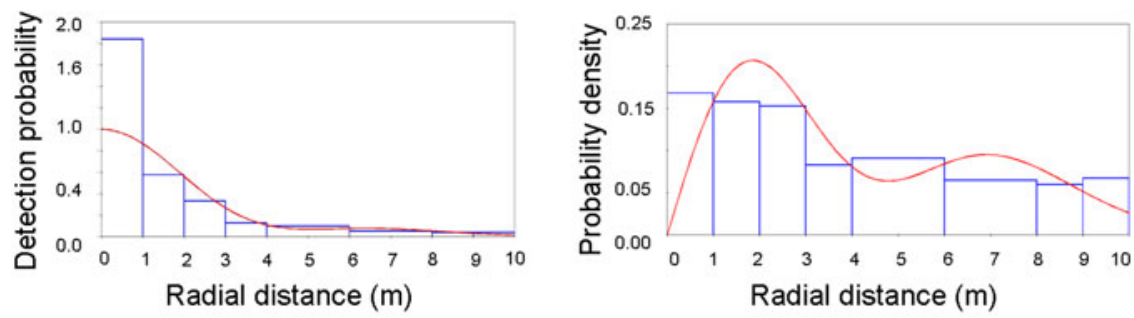

Bharal (winter)
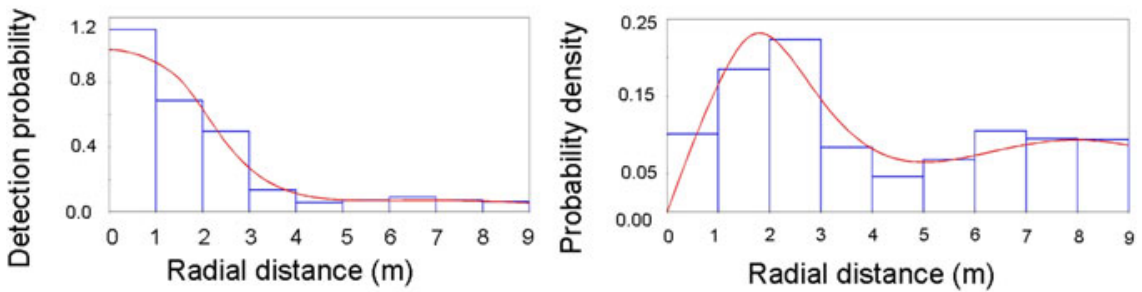

Musk deer (summer)
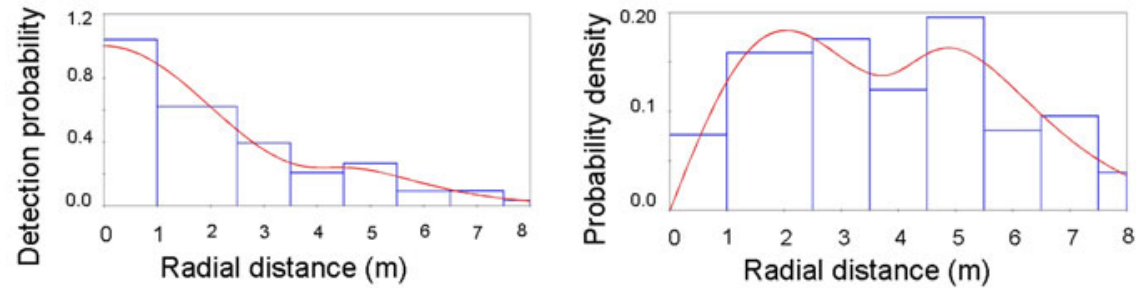

Musk deer (winter)
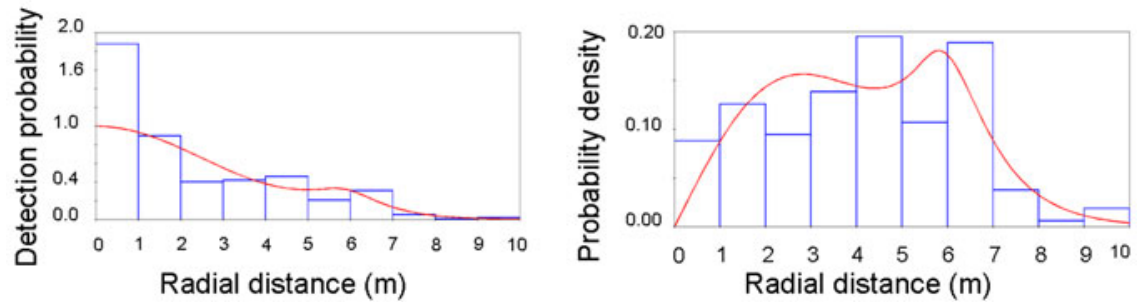

FIG. 3 Detection probability and probability density for the models selected for estimating density. The bars show the data distribution, and the line represents the model fit. The heights of the bars are scaled so that they cover the same total area as the area under the line, to show how well the detection function fits the data. densities in our study are low compared to those of Spiti can be expected because of differences in habitat type and topography. The Spiti landscape comprises vast trans-Himalayan meadows (Biotic Province 1B; Rodgers et al., 2000), whereas our study area consists primarily of narrow valleys and gorges with rough terrain and barren slopes (Biotic Province $1 \mathrm{C}$; Kumar et al., 2017; Plate 1). The differences of bharal density estimates and mean group sizes (9.6 in Nilang valley vs 13.1 in Kibber, Spiti) between these two areas may thus be a result of differences in habitat quality. In addition, Nilang valley is affected by anthropogenic disturbances such as hunting (Bhardwaj et al., 2010), livestock grazing (Chandola, 2009; RP pers. obs., 2017) and presence of free-ranging dogs (Pal et al., 2020). The differences could also be caused by different survey techniques. We were unable to estimate bharal density using the point count distance method because of insufficient observations. The double observer method used to estimate bharal density in trans-Himalayan habitat requires visual coverage of the entire survey area in a short period, a requirement that could not be fulfilled in our study because parts of the study area were inaccessible and visual coverage was insufficient (Plate 1).

The density of Himalayan musk deer was higher in summer (o.4 \pm SE 0.1 individuals $/ \mathrm{km}^{2}$ ) than winter (o.1 \pm SE 0.05 individuals $/ \mathrm{km}^{2}$ ). The analysis of seasonal habitat use in the study area also showed a trend of decline in captures at high elevations ( $\mathrm{Pal}$ et al., 2020) in winter, possibly because musk deer migrate to lower altitudes during periods of heavy snowfall. Similar seasonal movements were also observed in other areas (Anwar \& Minhas, 2008; Dendup \& Lham, 2018). Other studies using the silent drive count method in Kedarnath Wildlife Sanctuary estimated musk deer density to be $3.7 \pm \mathrm{SE} 0.2$ individuals $/ \mathrm{km}^{2}$ in 1989-1991 (Sathyakumar, 1994), 2.2 individuals $/ \mathrm{km}^{2}$ in 1994-1995 (Sathyakumar \& Malik, 2006) and 1.2 individuals $/ \mathrm{km}^{2}$ in 2000 (S. Sathyakumar, unpubl. data). These studies may have 
TABLE 1 Details of the top three models used to estimate the densities of the bharal Pseudois nayaur and the Himalayan musk deer Moschus leucogaster in summer and winter in the Upper Bhagirathi basin, Uttarakhand, India, showing key functions (defining parametric shapes for the detection function), adjustment types (to allow for departures from the parametric shape), the number of adjustment terms selected (order), overdispersion factor ( $\hat{C}$ ), Akaike's information criterion adjusted for overdispersion (QAIC), and density estimates with standard error (SE) and coefficient of variance (CV).

\begin{tabular}{|c|c|c|c|c|c|c|}
\hline Key function & Adjustment type & Order & $\hat{\mathrm{C}}$ & QAIC & Estimate \pm SE & $\mathrm{CV}$ \\
\hline \multicolumn{7}{|c|}{ Bharal (summer) } \\
\hline Hazard & & 0 & 2.93 & $1,083.87$ & $1.61 \pm 0.60$ & 0.38 \\
\hline Half normal & Hermite polynomial & 2 & 29.23 & 118.05 & $0.51 \pm 0.10$ & 0.31 \\
\hline Uniform & Cosine & 1 & 123.98 & 33.06 & $0.16 \pm 0.05$ & 0.30 \\
\hline \multicolumn{7}{|c|}{ Bharal (winter) } \\
\hline Hazard & Cosine & 1 & 5.51 & 626.89 & $0.64 \pm 0.20$ & 0.37 \\
\hline Half normal & Hermite polynomial & 2 & 8.71 & 400.63 & $0.64 \pm 0.20$ & 0.37 \\
\hline Uniform & Cosine & 2 & 31.24 & 118.95 & $0.35 \pm 0.10$ & 0.36 \\
\hline \multicolumn{7}{|c|}{ Musk deer (summer) } \\
\hline Hazard & Cosine & 1 & 6.30 & 287.50 & $0.42 \pm 0.10$ & 0.34 \\
\hline Half normal & & 0 & 8.12 & 381.97 & $0.29 \pm 0.10$ & 0.34 \\
\hline Uniform & Cosine & 1 & 9.63 & 279.80 & $0.26 \pm 0.10$ & 0.34 \\
\hline \multicolumn{7}{|c|}{ Musk deer (winter) } \\
\hline Hazard & Cosine & 1 & 4.28 & 172.03 & $0.10 \pm 0.05$ & 0.48 \\
\hline Half normal & & 0 & 4.54 & 119.78 & $0.10 \pm 0.05$ & 0.47 \\
\hline Uniform & Cosine & 1 & 4.67 & 142.58 & $0.08 \pm 0.03$ & 0.46 \\
\hline
\end{tabular}

overestimated musk deer densities as the drive count method is known for overestimating the density of animals (Takeshita et al., 2016). In addition, they were carried out in a small portion (c. $2.5 \mathrm{~km}^{2}$ ) of a protected area; small study areas combined with a bias towards good habitat quality can result in highly overestimated densities (Suryawanshi et al., 2019).

Our density estimates are associated with high coefficients of variation. This high variability is probably caused by landscape topography and species biology. The fit of the model for the solitary Himalayan musk deer was better than for the group-living bharal. Here, we discuss some of the issues we faced using sampling with camera traps, and make suggestions as to how these can be addressed in future studies.

For the bharal, the main problem that caused bias in the distances at which individuals were captured was the inadequate camera view because of slopes. The ruggedness of the landscape also influences the approach angle and the distance covered by the cameras: those on hilltops or at the base of a hill covered distances of $10-20 \mathrm{~m}$, whereas cameras on hill slopes covered distances of 6-10 $\mathrm{m}$ (depending on the slope). Topographic variability probably also influenced detection probability and the estimated angle of the camera view. Future studies in similar landscapes could use statistical tests to examine the effects of these parameters more thoroughly.

Another issue encountered with the group-living bharal was that animals grazing close to the camera blocked the view of animals that were further away. This can make it impossible to calculate the distance from the camera for individuals in the background, leading to a bias towards individuals recorded at shorter distances. However, such incidents were relatively rare in our study (six occasions). Herd behaviour also affects captures, as bharals tend to follow the first individual when moving together. Because we analysed individual distances from the camera, this can cause heaping in the distances recorded (Fig. 3).

Distance sampling with camera traps requires setting the cameras in burst or video mode. Our effort to implement this method in the Greater Himalayan alpine habitats failed because cameras were continuously triggered by grass movements in the field of view (RP, pers. obs., 2017). We had to discard data from four camera traps in this study for the same reason. Mounting cameras higher off the ground could help minimize this problem. In addition, the imprecise (high CV) estimates suggest that more sampling locations are required to improve precision (Howe et al., 2017; Cappelle et al., 2019).

The ability of camera sensors to detect moving animals may vary depending on camera type and placement, temperature, and humidity (Hofmeester et al., 2017). Different camera models can be tested at a site to assess the ability to detect animals. There could be inconsistencies between the theoretical and actual angle of view $\theta$, which can lead to biased estimates. This can result in underestimates if sensors are less sensitive to movements near the edges of the camera's field of view (i.e. the effective angle can be smaller than the assumed angle). This can be addressed with field tests to estimate the effective angle $\theta$, which can then be accounted for in the analysis. Imprecise measures of distance should not be an issue if they are appropriately binned in distances for the analysis (Buckland et al., 2015). However, 
imprecise estimates of the target species' availability for detection can cause erroneous estimates. Care should thus be taken in selecting the appropriate time period of animal activity and availability for detection (Howe et al., 2017).

Distance sampling with camera traps has paved the way for a new analytical approach to estimate the abundance of both group-living and solitary mountain ungulates in rugged and inaccessible terrains of the Himalaya. It can to some extent overcome the logistic constraints associated with rugged terrain and harsh weather that affect other methods such as point counts and transects sampling. These traditional methods are difficult to implement effectively in a high-altitude, rugged and remote landscape because they require cover of most vantage points in a single day or within a defined, short period of time (Singh \& Milner-Gulland, 2011). In addition, the low number of detections often limits the conventional analytical process. Indirect observations such as dung counts can be useful but require estimation of the decay rate, which is often difficult to obtain (Buckland, 2001; Kuehl et al., 2007). Distance sampling with camera traps can work for longer periods in the field and may help to overcome the challenges presented by low numbers of detections and observer bias (Cappelle et al., 2019). An important advantage of camera traps over conventional distance sampling is that they are better suited to monitor solitary, elusive and nocturnal species such as the Himalayan musk deer. Camera traps have been extensively used to survey the snow leopard Panthera uncia. A slight modification in the sampling design (modified camera placement) could help gain information on its main prey species, including the bharal, the ibex Capra sibirica, the argali Ovis ammon and the musk deer.

Despite these advantages, there are limitations to the use of camera traps, including the high cost of the cameras and the extensive time required to process photographs and videos. Substantial numbers of camera traps would be required to improve the precision of density estimates derived from distance sampling with camera traps (Cappelle et al., 2019). Despite the high initial cost, we believe this approach could help improve abundance estimations for both group living and solitary mountain ungulates in rough, mountainous terrain where conventional techniques cannot be implemented.

Acknowledgements This work is part of a project initiated under the National Mission for Sustaining the Himalayan Ecosystem (NMSHE) Programme funded by the Department of Science and Technology, Government of India (grant no.: DST/SPLICE/CCP/ NMSHE/TF-2/WII/2014[G]). The Miriam Rothschild Travel Bursary Programme provided funding for a 4-week internship for R. Pal with S. T. Buckland at St Andrews University, UK. We thank the Director and Dean of the Wildlife Institute of India for their guidance and support; D.V.S. Khati, Principal Chief Conservator of Forests and Chief Wildlife Warden, Uttarakhand, for granting research permission; Sandeep Kumar, Divisional Forest Officer and former Deputy Director, Gangotri National Park, and Shrawan Kumar for their support and cooperation; and L. Corlatti for reviewing the manuscript.
Author contributions Conception of study: SS, RP, TB, QQ; data collection: RP; data analysis: RP, STB, TB; writing: all authors; revisions: QQ, STB, SS.

\section{Conflicts of interest None.}

Ethical standards This work was carried out with permission from Uttarakhand Forest Department (Letter no. 836/5-6) and abided by the Oryx guidelines on ethical standards.

\section{References}

Anwar, M. \& Minhas, R.A. (2008) Distribution and population status of Himalayan musk deer (Moschus chrysogaster) in the Machiara National Park, AJ and K. Pakistan Journal of Zoology, 40, 159-163.

BAGCHI, S. \& Mishra, C. (2006) Living with large carnivores: predation on livestock by the snow leopard (Uncia uncia). Journal of Zoology, 268, 217-224.

BagChi, S. \& Ritchie, M.E. (2010) Herbivore effects on above- and belowground plant production and soil nitrogen availability in the trans-Himalayan shrub-steppes. Oecologia, 164, 1075-1082.

Bhardwaj, M., Uniyal, V.P. \& Sanyal, A.K. (2010) Estimating relative abundance and habitat use of Himalayan blue sheep Pseudois Nayaur in Gangotri National Park. Galemys: Boletín Informativo de la Sociedad Española para la Conservación y Estudio de los Mamíferos, 22, 545-560.

Bhattacharya, T. \& Sathyakumar, S. (2011) Natural resource use by humans and response of wild ungulates. Mountain Research and Development, 31, 209-220.

Bhattacharya, T., Bashir, T., Poudyal, K., Sathyakumar, S. \& SAHA, G.K. (2012a) Distribution, occupancy and activity patterns of goral (Nemorhaedus goral) and serow (Capricornis thar) in Khangchendzonga Biosphere Reserve, Sikkim, India. Mammal Study, 37, 173-181.

Bhattacharya, T., Kittur, S., Sathyakumar, S. \& Rawat, G.S. (2012b) Diet overlap between wild ungulates and domestic livestock in the Greater Himalaya: implications for management of grazing practices. Proceedings of the Zoological Society, 65, 11-21.

Buckland, S.T., Anderson, D.R., Burnham, K.P., LaAke, J.L., Borchers, D.L. \& Thomas, L. (2001) Introduction to Distance Sampling: Estimating Abundance of Biological Populations. Oxford University Press, Oxford, UK.

Buckland, S.T., Rexstad, E.A., Marques, T.A. \& Oedekoven, C.S. (2015) Distance Sampling: Methods and Applications. Springer International Publishing, Cham, Switzerland.

Burton, A.C., Neilson, E., Moreira, D., Ladle, A., Steenweg, R., Fisher, J.T. et al. (2015) Wildlife camera trapping: a review and recommendations for linking surveys to ecological processes. Journal of Applied Ecology, 52, 675-685.

Cappelle, N., Després-Einspenner, M., Howe, E.J., Boesch, C. \& KÜHL, H.S. (2019) Validating camera trap distance sampling for chimpanzees. American Journal of Primatology, 81, e22962.

Cavallini, P. (1992) Survey of the goral Nemorhaedus goral (Hardwicke) in Himachal Pradesh. Journal of Bombay Natural History Society, 89, 302-307.

Chandola, S. (2009) Vegetational inventory of cold desert habitat of Nilang area of Jadh Ganga catchment (Uttarkashi) in Garhwal Himalaya. PhD thesis, Hemvati Nandan Bahuguna Garhwal University, Uttarakhand, India.

Corlatti, L., Fattorini, L. \& Nelli, L. (2015) The use of block counts, mark-resight and distance sampling to estimate population size of a mountain-dwelling ungulate. Population Ecology, 57, 409-419. 
Dendup, P. \& Lham, C. (2018) Winter distribution and poaching of musk deer, Moschus chrysogaster and Moschus leucogaster in Jigme Dorji National Park, Bhutan. International Journal of Conservation Science, 9, 193-198.

Forsyth, D.M. \& Hickling, G.J. (1997) An improved technique for indexing abundance of Himalayan thar. New Zealand Journal of Ecology, 21, 97-101.

Green, M.J.B. (1985) Aspects of the ecology of the Himalayan musk deer. PhD thesis, University of Cambridge, Cambridge, UK.

Hofmeester, T.R., Rowcliffe, J.M. \& Jansen, P.A. (2017) A simple method for estimating the effective detection distance of camera traps. Remote Sensing in Ecology and Conservation, 3, 81-89.

Howe, E.J., Buckland, S.T., Després-Einspenner, M.L. \& Kühl, H.S. (2017) Distance sampling with camera traps. Methods in Ecology and Evolution, 8, 1558-1565.

Howe, E.J., Buckland, S.T., Després-Einspenner, M.L. \& Kühl, H.S. (2019) Model selection with overdispersed distance sampling data. Methods in Ecology and Evolution, 10, 38-47.

Jarvis, A., Guevara, E., Reuter, H.I. \& Nelson, A.D. (2008) Hole-Filled SRTM for the Globe, Version 4. CGIAR-CSI SRTM 9om Database, CGIAR Consortium for Spatial Information. srtm.csi.cgiar.org [accessed August 2016].

Kittur, S., Sathyakumar, S. \& Rawat, G.S. (2010) Assessment of spatial and habitat use overlap between Himalayan tahr and livestock in Kedarnath Wildlife Sanctuary, India. European Journal of Wildlife Research, 56, 195-204.

Kuehl, H.S., Todd, A., Boesch, C. \& Walsh, P.D. (2007) Manipulating decay time for efficient large-mammal density estimation: gorillas and dung height. Ecological Applications, 17, 2403-2414.

Kumar, A., Adhikari, B.S. \& Rawat, G.S. (2017) Biogeographic delineation of the Indian trans-Himalaya: need for revision. Current Science, 113, 1032-1033.

Laing, S.E., Buckland, S.T., Burn, R.W., Lambie, D. \& Amphlett, A. (2003) Dung and nest surveys: estimating decay rates. Journal of Applied Ecology, 40, 1102-1111.

McCarthy, K.P., Fuller, T.K., Ming, M., McCarthy, T.M., Waits, L. \& Jumabaev, K. (2008) Assessing estimators of snow leopard abundance. Journal of Wildlife Management, 72, 1826-1833.

McNaUghton, S.J. (1979) Grazing as an optimization process: grassungulate relationships in the Serengeti. The American Naturalist, $113,691-703$.

Mishra, C., van Wieren, S.E., Ketner, P., Heitkonig, I.M.A. \& Prins, H.H.T. (2004) Competition between domestic livestock and wild bharal Pseudois nayaur in the Indian trans-Himalaya. Journal of Applied Ecology, 41, 344-354.

Namgail, T., Fox, J.L. \& Bhatnagar, Y.V. (2007) Habitat shift and time budget of the Tibetan argali: the influence of livestock grazing. Ecological Research, 22, 25-31.

O’Neill, H. (2008) Designing robust ranger based monitoring strategies for the saiga antelope Saiga tatarica tatarica. $\mathrm{PhD}$ thesis, Imperial College London, London, UK.

Pal, R., Thakur, S., Arya, S., Bhattacharya, T. \& Sathyakumar, S. (2020) Mammals of the Bhagirathi basin, Western Himalaya: understanding distribution along spatial gradients of habitats and disturbances. Oryx, published online 20 July 2020.

Prater, S.H. (1980) The Book of Indian Mammals. Bombay Natural History Society, Mumbai, India.

Rodgers, W.A., Panwar, H.S. \& Mathur, V.B. (200o) Wildlife Protected Area Network in India: A Review. Executive summary, 1st edition. Wildlife Institute of India, Dehradun, India.

Rovero, F. \& Zimmermann, F. (2016) Camera Trapping for Wildife Research. Pelagic Publishing Ltd, Exeter, UK.
Roy le, J.A. (2004) $\mathrm{N}$-mixture models for estimating population size from spatially replicated counts. Biometrics, 6o, 108-115.

Royle, J.A. \& Nichols, J.D. (2003) Estimating abundance from repeated presence-absence data or point counts. Ecology, 84, 777-79o.

SATHYAKUMAR, S. (1994) Habitat ecology of major ungulates in Kedarnath Musk Deer Sanctuary. PhD thesis, Saurashtra University, Rajkot, Gujrat, India.

Sathyakumar, S. \& Bhatnagar, Y.V. (2002) Mountain Ungulates ENVIS Bulletin: Wildlife and Protected Areas. Wildlife Institute of India, Dehradun, India.

Sathyakumar, S., Bhattacharya, T., Bashir, T. \& Poudyal, K. (2013a) Developing Spatial Database on the Mammal Distributions and Monitoring Programme for Large Carnivores, Prey Populations, and their Habitats in Khangchendzonga Biosphere Reserve. Project report, Wildlife Institute of India, Dehradun, India.

Sathyakumar, S., Gopal, S.R. \& Johnsingh, A.J.T. (2013b) Musk deer. In Mammals of South Asia. Volume 2 (eds A.J.T. Johnsingh \& N. Manjrekar), pp. 223-241. Universities Press, Hyderabad, India.

Sathyakumar, S. \& Malik, P.K. (2006). Release of Captive Himalayan Musk Deer in Kedarnath Wildlife Sanctuary, Western Himalaya. Final report, Wildlife Institute of India, Dehradun, India.

Schaller, G.B., Junrang, R. \& Mingjiang, Q. (1988) Status of the snow leopard Panthera Uncia in Qinghai and Gansu Provinces, China. Biological Conservation, 45, 179-194.

Singh, N.J. \& Milner-Gulland, E.J. (2011) Monitoring ungulates in Central Asia: current constraints and future potential. Oryx, $45,38-49$.

SulKaVA, R.T. \& LiUkKo, U.M. (2007) Use of snow-tracking methods to estimate the abundance of otter (Lutra lutra) in Finland with evaluation of one-visit census for monitoring purposes. Annales Zoologici Fennici, 44, 179-188.

Suryawanshi, K.R., Bhatnagar, Y.V. \& Mishra, C. (2010) Why should a grazer browse? Livestock impact on winter resource use by bharal Pseudois nayaur. Oecologia, 162, 453-462.

Suryawanshi, K.R., Bhatnagar, Y.V. \& Mishra, C. (2012) Standardizing the double-observer survey method for estimating mountain ungulate prey of the Endangered snow leopard. Oecologia, $169,581-590$.

Suryawanshi, K.R., Khanyari, M., Sharma, K., Lkhagvajav, P. \& Mishra, C. (2019) Sampling bias in snow leopard population estimation studies. Population Ecology, 61, 268-276.

Suryawanshi, K.R., Mudappa, D., Khanyari, M., Raman, T.R.S., Rathore, D., Kumar, M.A. \& Patel, J. (2020) Population assessment of the Endangered Nilgiri tahr Nilgiritragus hylocrius in the Anamalai Tiger Reserve, using the double-observer survey method. Oryx, 55, 66-72.

Takeshita, K., Ikeda, T., Takahashi, H., Yoshida, T., Igota, H., MatsuURA, Y. \& Kaji, K. (2016) Comparison of drive counts and mark-resight as methods of population size estimation of highly dense sika deer (Cervus Nippon) populations. PLOS ONE, 11, eo164345.

Thomas, L., Buckland, S.T., Rexstad, E.A., Laake, J.L., Strindberg, S., Hedley, S.L. et al. (2010) Distance software: design and analysis of distance sampling surveys for estimating population size. Journal of Applied Ecology, 47, 5-14.

Timmins, R.J. \& Duckworth, J.W. (2015) Moschus leucogaster. In The IUCN Red List of Threatened Species 2015: e.T13901A61977764. dx.doi.org/10.2305/IUCN.UK.2015-2.RLTS.T13901A61977764.en [accessed 6 June 2020].

Yoccoz, N.G., Nichols, J.D. \& Boulinier, T. (2001) Monitoring of biological diversity in space and time. Trends in Ecology \& Evolution, 16, 446-453. 